\title{
Detecção de anticorpos para Toxoplasma gondii em soro de suínos criados e abatidos em frigoríficos da região da grande Porto Alegre-RS, Brasil ${ }^{1}$
}

\author{
Detection of antibodies against Toxoplasma gondii in sera from swine bred and slaughtered in \\ the great Porto Alegre-RS abbattoirs, Brazil.
}

\author{
Cristina Germani Fialho $^{2}$ FlávioAntônio Pacheco de Araujo ${ }^{3}$
}

\section{RESUMO}

No presente trabalho, objetivou-se contribuir com dados sobre a freqüencia de sororeagentes para Toxoplasma gondii em suínos criados e abatidos na Região da Grande Porto Alegre e fornecer subsídios sobre a importância da transmissão deste protozoário, por suínos. Foram coletadas amostras de 240 suínos em frigoríficos da região. A freqüência de anticorpos anti-Toxoplasma gondii, determinada através da técnica de hemaglutinação indireta, foi de $20 \%$ de soros iguais ou superiores a diluição 1:64. $\mathrm{Na}$ técnica de imunofluorescência indireta, foram encontrados $33,75 \%$ de soro com diluição iguais a 1:16 ou superiores.

Palavras-chave: Toxoplasma gondii; suínos; hemaglutinação indireta; imunofluorescência indireta

\section{ABSTRACT}

This report objectived to contribuite with data about the antibodies occurence of Toxoplasma gondii in swine bred and slaughtered in the area of Great Porto Alegre- RS, Brazil. The data should supply with subsidies on the importance of this protozoan transmission through swines. Samples were taken from 240 swines at slaughterhouses in that region. The frequency of anti-Toxoplasma gondii antibodies, determinanet through the indirect hemagglutination technic was of $20 \%$ of serum equal or superior to 1:64 dilution. In the indirect immunofluorescence technic was found $33.75 \%$ in serum with a diluition equal to 1:16 or superior.

Key words: Toxoplasma gondii, indirect immuno-fluorescence, swine, indirect hemagglutination.

\section{INTRODUÇÃO}

O Toxoplasma gondii é um coccídio que pode ser encontrado de três formas: taquizoítos, bradizoítos ou cistos teciduais e oocistos, este último somente no intestino dos felídeos, que são os hospedeiros definitivos. Os hospedeiros intermediários são várias espécies animais incluindo o ser humano (DUBEY, 1998).

O gato é considerado a principal fonte de infecção para suínos, e demais espécies de vertebrados, através da contaminação da água e ração com oocistos (VIDOTTO et al., 1990; ARAUJO, 1999). Os suínos podem, também, ingerir cistos teciduais comendo roedores infectados ou carne infectada, oferecida na forma de restos, ou adquirir infecção transplacentária (GIRALDI et al., 1991; LINDSAY et al., 1992).

A toxoplasmose é uma zoonose e pode causar, em humanos, linfadenopatia, encefalite em indivíduos imunodeprimidos, particularmente nos portadores de AIDS (Síndrome da Imunodeficiência Adquirida) e grave infecção pré-natal, quando a primoinfecçcão ocorre durante a gestação (ACHA \& SZYFRES, 1987). O risco da infecção de seres humanos através do consumo de carnes cruas ou mal cozidas, vem sendo relatado por autores como VIDOTTO et al. (1990), NAVARRO et al. (1992) e GARCIA et al. (1999).

\footnotetext{
${ }^{1}$ Financiado em parte pelo CNPq. Rio Grande do Sul (UFRGS). E-mail:cristinafialho@bol.com.br autor para correspondência.

${ }^{3}$ Professor Adjunto, Departamento de Patologia Clínica, Faculdade de Veterinária, UFRGS.
}

${ }^{2}$ Médico Veterinário, Mestrando do Curso de Pós-graduação em Ciências Veterinárias, Faculdade de Veterinária, Universidade Federal do 
Os recursos sorológicos usualmente utilizados para o diagnóstico da toxoplasmose incluem a hemaglutinação indireta (HAI), descrita pela primeira vez por JACOBS \& LUNDE (1957), como uma técnica que revela constituintes citoplasmáticos de origem protéica, e a imunofluorescência indireta (IFI), que revela anticorpos IgM ou IgG, dirigidos contra os antígenos de superfície do T. gondii, de acordo com o conjugado anti-gamaglobulina utilizado (CAMARGO, 1974). No Brasil, vários autores realizaram estudo sorológico utilizando essas técnicas para suínos (Tabela 1).

Os estudos de prevalência de $\boldsymbol{T}$. gondii na espécie suína têm grande relevância por ser esta espécie considerada uma das principais fontes de infecção para a espécie humana, especialmente pela ingestão de carne mal cozida (DAVIES et al., 1998). Estes estudos servem para avaliar, além da ocorrência desta infecção, o risco a que estão expostos os humanos que ingerem carne em determinada região (ISHIZUKA, 1978; D'ANGELINO \& ISHIZUKA, 1986).

O presente trabalho objetivou especificamente, estabelecer a freqüência de sororeagentes, em suínos abatidos em matadouros, da região da Grande Porto Alegre - RS, pelas técnicas de IFI e HAI e comparar as duas técnicas diagnósticas pelos resultados obtidos, através de análise estatística.

\section{MATERIAL E MÉTODOS}

Foram utilizados, neste estudo, 240 suínos, criados e abatidos em municípios da região da Grande

Tabela 1 : Freqüências de suínos sororeagentes ao Toxoplasma gondii detectadas por vários autores, pelas técnicas de Hemaglutinação indireta e Imunofluorescência indireta, no período de 1975 a 2001 no Brasil.

\begin{tabular}{|c|c|c|c|}
\hline REFERÊNCIAS & ESTADO & TÉCNICA & PORCENTAGEM \\
\hline AMARAL, SANTOS \& REBOUÇAS (1975) * & SP e RS & HAI $\dot{s}$ & $22,8 \%$ \\
\hline SCHENK, LIMA \& VIANA (1976) * & MG & IFI $\odot$ & $29,9 \%$ \\
\hline CORREA, SALATA \& OLIVEIRA (1978) * & SP & IFI * & $22,5 \%$ \\
\hline ISHIZUKA $(1978) *$ & SP & IFI $\otimes$ & $32,8 \%$ \\
\hline SANTOS, AMARAL \& REBOUÇAS (1978) & SP & HAI 䊣 & $24,68 \%$ \\
\hline \multirow[t]{4}{*}{ VASCONCELOS, COSTA \& ÁVILA (1979) } & SP & IFI $\otimes$ & Leitões $52,17 \%$ \\
\hline & & & Crescimento $48,83 \%$ \\
\hline & & & Fêmeas $45,83 \%$ \\
\hline & & & Terminação 45,40\% \\
\hline SILVA et al., (1981)* & RS & HAI 拳 & $7,2 \%$ \\
\hline CHAPLIN et al., (1984) & RS & HAI 橉 & $7,4 \%$ \\
\hline PASSOS \& FIGUEIREDO (1984) * & MG & IFI $\otimes$ & $33,4 \%$ \\
\hline \multirow[t]{4}{*}{ D’ANGELINO \& ISHIZUKA (1986) } & MG & IFI $\odot$ & Intensivo $54 \%$ \\
\hline & & & Semi-intensivo $49,2 \%$ \\
\hline & & HAI 楼 & Intensivo $46 \%$ \\
\hline & & & Semi-intensivo $42,7 \%$ \\
\hline VIDOTTO et al., (1986) * & PR & IFI潾 & $34,62 \%$ \\
\hline$(1990)$ & PR & IFI䅈 & $37,84 \%$ \\
\hline WENTZ, SOBESTIANSKY \& CHAPLIN (1988) & $\mathrm{SC}$ & HAI萧 & $1,16 \%$ \\
\hline GUIMARÃES et al., (1992) & MG & IFI $\otimes$ & $90,4 \%$ \\
\hline GRÜNSPAN et al., (1995) * & RS & HAI 䊉 & $18 \%$ \\
\hline \multirow[t]{2}{*}{ SOUZA (1995) * } & RJ & HAI 宷 & $0,79 \%$ \\
\hline & & IFI $\odot$ & $0,88 \%$ \\
\hline GARCIA et al., (1999) & PR & IFI 䊝 & $24 \%$ \\
\hline MATOS et al., (1999) & GO & $\mathrm{HAI}$ 档 & $27,74 \%$ \\
\hline ARAUJO (1999) ** & RS & IFI $\otimes$ & $7,3 \%$ \\
\hline TSUTSUI et al., (2001) & PR & IFI 潾 & $15,35 \%$ \\
\hline
\end{tabular}

* autores que realizaram suas coletas em matadouros.

** autores que realizaram coleta de parte da amostra em matadouros.

\& autores que consideraram a diluição positiva a partir de 1:16

* autores que consideraram a diluição positiva a partir de 1:20

* autores que consideraram a diluição positiva a partir de 1:64

¿ts autores que consideraram a diluição positiva a partir de 1:256

Ciência Rural, v. 33, n. 5, set-out, 2003. 
Porto Alegre. Essa amostragem foi realizada de acordo com THRUSFIELD (1986), para uma expectativa de freqüência de $20 \%$, com uma precisão absoluta de $5 \%$ e um nível de confiança de $95 \%$. As coletas e os exames de sangue foram efetuados durante o período de novembro de 2000 a julho de 2001. A coleta de sangue foi feita por ocasião da sangria, em copos plásticos descartáveis, que foram mantidos levemente inclinados em bandeja com areia, à temperatura ambiente, para aguardar a coagulação. As amostras séricas foram acondicionadas em frascos de vidro apropriados e estocadas à temperatura de $-20^{\circ} \mathrm{C}$, para posterior análise sorológica.

Os exames foram realizados no Laboratório de Protozoologia da Universidade Federal do Rio Grande do Sul e no Laboratório Central do Estado do Rio Grande do Sul (Lacen-RS). A técnica de HAI foi realizada segundo o Kit HAP-Toxoplasmose ${ }^{\text {a }}$, sendo os critérios de positividade adotados conforme SILVA et al. (1981) e CHAPLIN et al. (1984). A técnica de Imunofluorescência foi realizada de acordo com a técnica descrita por CAMARGO (1974) com as alterações realizadas por ARAUJO (1999).

Os resultados foram submetidos à análise estatística, sendo que para tal se utilizou o Teste Quiquadrado, com o auxílio do programa estatístico Graphpad Instat.

\section{RESULTADOS E DISCUSSÃO}

Utilizando a técnica de Hemaglutinação indireta, observou-se que dos 240 suínos, 48 apresentaram títulos iguais ou superiores a 1:64 representando freqüência de $20 \%$ de soropositivos e 192 foram negativos perfazendo $80 \%$. Pela técnica de IFI, dos 240 suínos, 81 apresentaram títulos iguais ou superiores a 1:16 representando $33,75 \%$ de soropositivos e 159 foram negativos totalizando $66,25 \%$. O teste Qui-quadrado aplicado aos dados da tabela 2 revelou haver diferença estatisticamente significativa, entre as duas técnicas, HAI e IFI $(\mathrm{p}=0,0010)$.

Tabela 2 -Resultados sorológicos das técnicas de Hemaglutinação indireta (HAI) e Imunofluorescência indireta (IFI), para Toxoplasmose em suínos abatidos em matadouros da Região da Grande Porto Alegre, RS, Brasil.

\begin{tabular}{lccc}
\hline $\begin{array}{c}\text { TÉCNICA/ } \\
\text { RESULTADO }\end{array}$ & POSITIVO & NEGATIVO & TOTAL \\
\hline HAI & $48(10 \%)$ & $192(40 \%)$ & $240(50 \%)$ \\
IFI & $81(17 \%)$ & $159(33 \%)$ & $240(50 \%)$ \\
TOTAL & $129(27 \%)$ & $351(73 \%)$ & $480(100 \%)$ \\
\hline
\end{tabular}

Valores de prevalência menos expressivos que os do presente trabalho foram observados, em várias regiões do Brasil por SCHENK et al., (1976), CORREA et al., (1978) e GARCIA et al. (1999), e TSUTSUI et al. (2001), pela IFI. As taxas bem mais baixas, encontradas por CHAPLIN et al. (1984) e SILVA et al. (1981), no RS, WENTZ et al., (1988), em SC, pela técnica de HAI e, ainda, a de ARAUJO (1999), RS, utilizando a técnica de IFI, e SOUZA (1995), no RJ, utilizando as duas técnicas, torna discutível a importância da carne suína como principal via de transmissão da doença, nestas regiões. WENTZ et al., (1988) e SOUZA (1995) relacionaram os mais baixos valores de prevalência encontrados ao maior cuidado dispensado pelos produtores de suínos de pedigree, ao uso de rações industriais não contaminadas, a um controle mais efetivo dos roedores e a um sistema de limpeza e desinfecção mais rigoroso.

Pode-se verificar que os dados estão de acordo, no Brasil, com os de AMARAL et al. (1975) e GRÜNSPAN et al. (1995), que utilizaram a técnica de HAI, e ainda, com os dados de ISHIZUKA (1978), PASSOS \& FIGUEIREDO (1984), e VIDOTTO et al. (1986), realizados pela técnica de IFI.

Outros autores como VASCONCELOS et al., (1979), VIDOTTO et al. (1990), GUIMARÃES et al. (1992) encontraram taxas de prevalência mais elevadas pela IFI, enquanto SANTOS et al. (1978) e MATOS et al. (1999) detectaram maior número de reagentes pela HAI, e D'ANGELINO \& ISHIZUKA (1986) observaram níveis de prevalência bem elevados utilizando as duas técnicas.

Em outros países, também há trabalhos de vários autores. Concordando com os dados pode-se citar MORENO et al. (1985), em Córdoba-Espanha (32\%), pela técnica de IFI. PAINE (1969) nos EUA obteve pela técnica de HAI apenas 4,05\% de suínos positivos, semelhante ao encontrado por TIMOFEYEV (1971), 5,1\%, utilizando a IFI. Na Austria, a prevalência de anticorpos anti-T. gondii em suínos foi testada pela IFI por EDELHOFER (1994), tendo encontrado em porcas de cria no ano de 1982 $13,7 \%$ e em 1992, 4,3\% e em suínos de engorda em 1982, 43,4\% e em 1992, 0,8\%. ARIAS et al. (1994), na Costa Rica obtiveram prevalência de anticorpos IFI-IgG anti-T. gondii de 43,8\%. DUBEY et al. (1995), verificando vários testes sorológicos para a detecção de infecção por $\boldsymbol{T}$. gondii em suínos naturalmente infectados, encontrou pela técnica de HAI $6,4 \%$ de positivos.

Quanto à utilização das técnicas, concordase com CAMARGO et al. (1986) de que a HAI é de execução simples (kit pronto, com todas as instruções), 
fornecendo resultados em curto prazo e de baixo custo. Segundo LARSON (1989), a hemaglutinação indireta mede anticorpos que persistem por anos, mas aparecem mais tardiamente. Por esse motivo, não é indicada para diagnóstico e sim como screening. A utilização da IFI no diagnóstico, inquéritos e levantamentos epidemiológicos tem sido de aceitação universal, tanto para a espécie humana como para outras espécies animais, por ser considerada de fácil realização e de grande sensibilidade (ARAUJO, 1999). Outra vantagem dos ditos testes é serem praticamente isentos de problemas de infecção acidental por laboratoristas, não requerem organismos vivos (URQUHART et al., 1998; ARAUJO, 1999). O inconveniente da IFI, salientado por CORCUERA et al. (1981) é necessitar pessoal especializado para a interpretação dos resultados, além do alto preço do microscópio de imunofluorescência.

\section{CONCLUSÕES}

A freqüência de resultados positivos de anticorpos anti-T. gondii no soro dos suínos que fizeram parte deste estudo foi de $20 \%$ pela técnica de hemaglutinação indireta e $33,75 \%$ pela técnica de imunofluorescência indireta. Os suínos criados e abatidos nesta região podem ser considerados uma fonte de infecção de T. gondii para seres humanos.

\section{AGRADECIMENTOS}

Os autores agradecem a valiosa colaboração da Profa. Dra. Silvia Maria Spalding e do LACEN-RS, na execução da técnica de Imunofluorescência indireta.

\section{FONTES DE AQUISIÇÃO}

a - HAP-Toxoplasmose: SALCK Ind. E Com. Prod. Biológicos Ltda. R. Arapuã,201, Vila Guarani, 04307070, São Paulo-SP, Brasil.

\section{REFERÊNCIAS BIBLIOGRÁFICAS}

ACHA, P.N.; SZYFRES, B. Zoonoses and comunicable diseases common to man and animals. Washington : Pan American Health Organization / World Health Organization, 1987. 963p. (Scientific Publication, n. 503).

AMARAL, V. DO.; SANTOS, S.M.; REBOUÇAS M.M. Estudos preliminares sobre a prevalência de anticorpos antitoxoplasma, por hemaglutinação, em soros de suínos provenientes dos Estados de São Paulo e Rio Grande do Sul, Brasil. O Biológico, n.41, p.105-107, 1975.

ARAUJO, F.A.P. de. Avaliação soroepidemiológica de anticorpos para Toxoplasma gondii Nicolle \& Manceaux, 1909 em soros de suínos (Sus scrofa) da região da Grande Erechim,
RS - Brasil, detectados através das técnicas de imunofluorescência indireta de imunoenzimática. 1999. 125f. Tese (Doutourado na área de Protozoologia) - Instituto Oswaldo Cruz.

ARIAS, Ma. L. Seroepidemiology of Toxoplasma gondii (Apicomplexa) in meat producing animals in Costa Rica. Rev Biol Trop, v.42, no. $1 / 2$, p.15-20, 1994.

CAMARGO, M.E. Introdução as técnicas de imunofluorescência. Rev Bras Patol Clín, v.10, n.3, p.87-107, 1974.

CAMARGO, M.E. et al. Um teste prático para a sorologia da toxoplasmose: o teste de hemaglutinação. Estudo comparativo com os testes de imunofluorescência e imunoenzimático de captura de IgM. Rev Bras Patol Clín, v.22, n.6, p.196-200, 1986.

CHAPLIN, E.L. et al. Cadeia epidemiológica de toxoplasmose em Guaporé, RS, relacionando humanos e seus animais domésticos. Arq Fac Vet UFRGS, v.12, p.25-34, 1984.

CORCUERA, M.T.; LOZANO J.; LOPEZ, F.R.F. Estudio comparativo de las distintas técnicas serológicas utilizadas para el diagnóstico de la toxoplasmosis. Rev Sanid Hig Publ, v.55, p.1045-1059, 1981.

CORREA, F.M.A.; SALATA, E.; OLIVEIRA, M.R. Toxoplasma gondii: diagnóstico, pela prova de imunofluorescência indireta em suínos no estado de São Paulo, Brasil. Arq Instit Biológ São Paulo, v.45, n.4, p.209-212, 1978.

D’ANGELINO, J.L.; ISCHIZUKA, M.M. Toxoplasmose suína. III. Avaliação da prevalência de infecção toxoplásmica em rebanhos suínos pela prova de imunofluorescência indireta e hemaglutinação. Bol Ofic Sanit Panam, v.100, n.6, p.634-647, 1986.

DAVIES, P.R. et al. Seroprevalence of Toxoplasma gondii and Trichinella spiralis in fishing swine raised in different production sistems in North Carolina, USA. Prev Vet Med, v.36, p.67-76, 1998.

DUBEY, J.P. Toxoplasmosis, sarcocystosis, isosporosis, and cyclosporosis. In: PALMER, S.R.; SOULSBY, L.; SIMPSON, D.I.H. Zoonoses. Oxford : Oxford University, 1998. 948p.

DUBEY, J.P. et al. Sensitivity and specificity of various serologic tests for detection of Toxoplasma gondii infection in naturaly infected sows. Am J Vet Res, v.58, n.8, p.10301036, 1995.

EDELHOFER, R. Prevalence of antibodies against Toxoplasma gondii in pigs in Austria- na evaluation of data from 1982 and 1992. Parasitol Res, n.80, p.642-644, 1994.

GARCIA, J.L. et al. Soroprevalência do Toxoplasma gondii, em suínos, bovinos, ovinos e eqüinos, e sua correlação com humanos, felinos e caninos, oriundos de propriedades rurais do norte do Paraná - Brasil. Ciência Rural, v.29, n.1, p.91-97, 1999.

GIRALDI, N. et al. Toxoplasmose congênita natural em suínos na região de Londrina, PR. Rev Bras Parasitol Vet, v.1, p.1- 5, 1991.

GRÜNSPAN, E.D. et al. Imunoglobulinas antitoxoplásmicas e retinocoroidite em suínos. Ciência Rural, v.25, n.2, p.261-264, 1995. 
GUIMARÃES, A.M. et al. Freqüência de anticorpos antiToxoplasma gondii em suínos da raça Piau. Arq Bras Med Vet Zootec, v.44, n.1, p.69-71, 1992.

ISHIZUKA, M.M. Avaliação da freqüência de reagentes ao Toxoplasma gondii, pela prova de imunofluorescência indireta em suínos de matadouro do município de São Paulo. Rev Fac Vet Zootec USP, v.15, n.2, p.151-154, 1978.

JACOBS, L.; LUNDE, M.N. A hemagglutination test for toxoplasmosis. J Parasitol, v.43, n.3, p.151-154, 1957.

LARSSON, C.D. Diagnóstico laboratorial da toxoplasmose reações utilizadas e interpretação clínica. Cães e Gatos, jan/fev, ano 4, n.24, p.5-11, 1989 .

LINDSAY, D.S.; BLAGBURN, B.L.; STUART, B.P. Toxoplasmosis (Toxoplasma gondii). In: LEMAN, A.D. et al Diseases of swine. 7.ed. Ames : Iowa States University, 1992. $1021 \mathrm{p}$

MATOS, M.P.C. et al. Anticorpos para Toxoplasma gondii em soros de matrizes suínas de granjas que abastecem o mercado consumidor de Goiânia. A Hora Veterinária, Ano 19, n.109, p.9-11, 1999.

MORENO, T.; MARTINEZ-GÓMES, F.; HERNÁNDEZRODRIGUES, S. Toxoplasmosis in pigs in Córdoba, Spain. Annals of Trop Med and Parasitol, v.79, n.3, p.271-273, 1985

NAVARRO, I.T. et al. Resistência do Toxoplasma gondii ao cloreto de sódio e aos condimentos em lingüiça de suínos. Bol Ofic Sanit Panam, v.112, n.2, p.138-143, 1992.

PAINE, G.D. Toxoplasmosis in lower mammals. J Protozool, v.16, n.2, p.371-372, 1969.

PASSOS, L.M.F.; FIGUEIREDO, B.L. Determinação da infecção por Toxoplasma gondii em bovinos e suínos abatidos em Belo Horizonte, Minas Gerais para se conhecer a freqüência de anticorpos e tentativa de isolamento a partir de músculos de bovino. In: CONGRESSO BRASILEIRO DE MEDICINA VETERINÁRIA, 19., 1984, Belém. Anais... Belém-Pa : Sociedade Brasileira de Medicina Veterinária, 1984. p. 378

SANTOS, S.M; AMARAL, V. do; REBOUÇAS, M.M. Prevalência de anticorpos antitoxoplasma, por hemaglutinação indireta, em soros de suínos provenientes de diferentes municípios do estado de São Paulo. O Biológico, n.XLIV, p.149-153, 1978.

SCHENK, M.A.M.; LIMA, J.D.; VIANA, F.C. Freqüîncia e isolamento de Toxoplasma gondii em suínos do Estado de Minas Gerais. 1976. ni. Tese (Doutorado) - Escola de Veterinária da UFMG.

SILVA, N.R.S. et al. Determinação de anticorpos toxoplásmicos em soros obtidos em matadouros, na região do Alto Taquarí, RS, Brasil. Arq Fac Vet UFRGS, v.9, p.33-38, 1981.

SOUZA, W.J.S. Epidemiologia da toxoplasmose: avaliação sorológica de suínos e trabalhadores em abatedouros na mesorregião do Grande Rio de Janeiro. 1995. 125f. Tese (Doutourado em parasitologia) - Instituto Oswaldo Cruz.

THRUSFIELD, M. Veterinary epidemiology. Great Britain: Butterworth, 1986. 483p.

TIMOFEYEV, B.A. Comparative study of CFT and IFI for diagnosis of toxoplasmosis in farn animals. In: CONGR. SOVIET. SOC. PROTOZOOL., 1971, Banku. Proceedings... Banku, ni, 1971. p.262-263.

TSUTSUI, V.S. et al. Estudo soroepidemiologico e fatores associados à transmissão do Toxoplasma gondii em granjas de suínos do norte do Estado do Paraná. J Bras Patol, v.37, n.4, p.255, 2001.

URQUHART, G.M. et al. Parasitologia veterinária. 2.ed. Rio de Janeiro : Guanabara, 1998. 273p.

VASCONCELOS, O.T.; COSTA, A.J.; ÁVILA, F.A. Aspectos epidemiológicos da infecção por Toxoplasma gondii em suínos. Científica, v.7, p.83-87, 1979.

VIDOTTO, O. et al. Prevalência de Toxoplasma gondii em suínos abatidos em matadouros no Norte do Paraná. In: ENCONTRO DE PESQUISAS VETERINÁRIAS, 2., 1986, Londrina. Anais... Londrina : UEL, 1986. p.23.

VIDOTTO, O. et al. Estudos epidemiológicos da toxoplasmose em suínos da região de Londrina-PR. Semina, v.11, n.1, p.53-59, 1990.

WENTZ, I., SOBESTIANSKY, J., CHAPLIN, E. Prevalência de anticorpos para toxoplasmose em soros de suínos de pedigree em Santa Catarina. Empresa Brasileira de Pesquisa Agropecuária, Concórdia: 1988, 3p. Comunicado Técnico, n. 130. 